\title{
Ordem cultural e desenvolvimento local participativo: estrutura para a prática do terapeuta ocupacional
}

\author{
Ricardo Lopes Correia, Camila Santiago da Rocha \\ Departamento de Terapia Ocupacional, Faculdade de Medicina, Universidade Federal do Rio de Janeiro - UFRJ, \\ Rio de Janeiro, RJ, Brasil.
}

\begin{abstract}
Resumo: A Ordem Cultural é compreendida como a expressão de um jogo de determinações de interdependências entre grupos sociais locais e globais, pares identificados pelas produções, valores e comportamentos que orientam de forma consciente os projetos de vida e a expansão das liberdades de um coletivo. A partir de uma pesquisa em Ciências Sociais e com marcos teóricos de Nobert Elias e Amartya Sen, este artigo objetiva apresentar uma estrutura teórico-prática da abordagem em desenvolvimento local participativo - DLP para o terapeuta ocupacional em torno da construção de projetos de vida coletiva, para que operacionalize na prática a questão comunitária, compreendida como as forças que singularizam a participação. Discute-se o uso da abordagem em DLP para o terapeuta ocupacional em uma estrutura flexível, que visa garantir o seu domínio, a Ocupação Humana, e o conjunto de intervenções, Tecnologias, sustentadas no manejo das atividades da vida cotidiana.A abordagem em desenvolvimento local participativo se apresenta como um importante arcabouço estrutural para ações comunitárias, e cabe ao terapeuta ocupacional ser um articulador das dimensões da Ordem Cultural local, para agenciar com a população-alvo de seu trabalho processos de continuidade em projetos de vida coletiva e de expansão de liberdades.
\end{abstract}

Palavras-chave: Cultura, Desenvolvimento Local, Ocupação, Participação Social, Terapia Ocupacional/tendências.

\section{Cultural order and participatory local development: structure for the occupational therapist practice}

\begin{abstract}
The Cultural Order is understood as the expression of a game of interdependencies determinations between local and global social groups, pairs identified by productions, values and behavior that consciously guide the life projects and the expansion of a collective freedom. Based on a Social Science research and with theoretical mark of Nobert Elias and Amartya Sen, this article aims to present a theoretical-practice structure of the approach in participatory local development- PLD to the occupational therapist surround by the construction of collective life projects, in order to operationalize in the practice of the community question, understood as the strengths that singularize the participation. We discuss the use of the PLD approach to the occupational therapist in a flexible structure, aiming to guarantee its domain, the Human Occupation, and the set of interventions, technologies, sustained in the management of the activities of daily living. The approach in participatory local development presents itself as an important structural outline to the community actions, and it is the occupational therapist role to be an articulator of the Local Cultural Order dimensions, to deal with the target population their work processes of continuity in collective life projects and expansion of freedom.
\end{abstract}

Keywords: Culture, Local Development, Occupation, Social Participation, OccupationalTherapy/tendencies.

\footnotetext{
Autor para correspondência: Ricardo Lopes Correia, Departamento de Terapia Ocupacional, Centro de Ciências da Saúde, Faculdade de Medicina da Universidade Federal do Rio de Janeiro, Bloco K, Sala 26, Rua Prof. Rodolpho Paulo Rocco, s/n, Cidade Universitária, Ilha do Fundão, CEP 21910-590, Rio de Janeiro, RJ, Brasil, email: toobiis@gmail.com
}

Recebido em Maio 07, 2015; $1^{\text {a }}$ Revisão em Ago. 30, 2015; 2a Revisão em Out. 01, 2015; Aceito em Nov. 10, 2015. 


\section{Fundamentos sobre o desenvolvimento local participativo}

O desenvolvimento local participativo - DLP, segundo Martins (2002), é uma abordagem estratégica de planejamento e um campo de açóes que promove o protagonismo humano comunitário em uma dada escala e natureza territorial, ampliando e fortalecendo as capacidades e as potencialidades dos agentes envolvidos, a fim de superar a pobreza e as privaçóes cotidianas, assim como garantir o desejo de viver individual e coletivamente num mesmo local. O DLP é uma abordagem orientada pela vida diária local e a participaçáo, ambos expressos em projetos de vida coletiva.

A preocupaçáo com o desenvolvimento, segundo Félix et al. (2009), surge no mundo a partir dos resultados desastrosos a vida humana, causados pela Segunda Guerra Mundial, bem como diante de propostas de reorganização e recuperação de países, especialmente da Europa, que adotavam um modelo strito senso, focalizado no enriquecimento econômico e na orientação de modelos de países já industrializados. Para o autor, a conclusão deste processo foi o "[...] seu relativo fracasso e o insucesso dos principais paradigmas de crescimento econômico e de desenvolvimento a elas vinculados" (FELIX et al., 2009. p. 19).

No final da década de 1970, Silveira (2008) argumenta que foi através da Organização das Nações Unidas (ONU) que começou a ser discutida uma ideia de desenvolvimento que garantisse a participação das pessoas envolvidas nas situaçóes de vulnerabilidades e a consequente aplicaçáo de modelos e estruturas de projetos para o enfrentamento da pobreza extrema e da incapacidade de autogerenciamento político de países afetados pelo intenso processo de industrializaçáo e capitalismo. A partir desse momento surgem modelos de desenvolvimento em escalas global, regional e local, com naturezas distintas, como o desenvolvimento sustentável, territorial e solidário, todos ainda na focalização do aumento econômico.

Porém, para Sen (2000), o desenvolvimento pensado além da lógica economicista começa a ser rediscutido na década de 1990 e passa a ser compreendido como um processo de expansão das liberdades, o que para este economista indiano está diretamente relacionado à melhoria da qualidade de vida das pessoas, na força que as capacidades humanas agenciam processos de mudanças em âmbito local e global, nas esferas individuais e sociais.
Para Martins (2002, p. 52), após duas décadas de experiências frustradas em desenvolvimento local na lógica de "progresso econômico" associado à qualidade de vida, diversos representantes políticos e estudiosos compreenderam que o desenvolvimento local "[...] deveria ser uma ação de enfrentamento real às piores manifestaçôes de pobreza, objetivando a igualdade de opções e não de renda". Esta avaliação tardia revelou que as oportunidades de escolha, a liberdade e as razóes individuais e coletivas para a determinação de quais tipos de vida as pessoas gostariam de seguir, denominados projetos de vida, passaram a ser o núcleo conceitual e prático de açóes em desenvolvimento local.

O terapeuta ocupacional, como um profissional dedicado ao estudo e intervenção da ocupação humana, possui capacidade de agenciar projetos de vida coletiva orientado pela abordagem em desenvolvimento local participativo sob a base da Cultura, uma vez que compreende sua prática aos interesses individuais e coletivos no contexto sociocultural de que fazem parte, buscando fomentar as capacidades humanas, o desempenho ocupacional.

Com isso, este artigo tem por objetivo propor a abordagem teórico-prática em desenvolvimento local participativo - DLP para terapeutas ocupacionais que queiram dedicar a sua prática nas questóes comunitárias e nas transformaçóes do local, em que o contexto onde as pessoas tecem suas relaçóes, participaçóes e historicidades estejam num campo de tensões e interdependências, compreendidas como Ordem Cultural. Parte-se de uma pesquisa em ciências sociais, utilizando as concepçôes de Nobert Elias e Amartya Sen, como fundamentais marcos teóricos para as pesquisas em desenvolvimento.

\section{Ordem Cultural e jogo de determinações: contribuições de Nobert Elias}

A Ordem Cultural é compreendida como a expressão de um jogo de determinaçôes de interdependências entre grupos sociais locais e globais, pares identificados pelas produçóes, valores e comportamentos que orientarão projetos em desenvolvimento local participativo.

Trata-se de uma estrutura objetiva e subjetiva que, segundo Elias (1970), determina os processos de manutenção e transformação da sociedade ao longo do tempo, num diálogo constante e indissociável entre o nível local e global, individual e social. 
Neste artigo, elege-se uma concepção de Ordem Cultural (com letra maiúscula), a partir da concepção de Nobert Elias, localizado na Sociologia Política, que mais se aproxima, por nós, dos interesses aqui apresentados para o desenvolvimento local participativo. Este autor busca na História Cultural, como afirma Ribeiro (2005)1, os pressupostos de determinação, interdependência, identidades e personalidades que irão gerar padrôes de mudanças sociais significativos ao longo do tempo.

A compreensão de Ordem Cultural para Nobert Elias, segundo Aquino (2012), está no conceito de civilizaçáo, modo como a sociedade ocidental toma consciência de si mesma, ao longo do tempo, a partir das experiências individuais e coletivas no campo Cultural.

Para Eagleton (2011), acompanhando a visão eliasiana (de Nobert Elias), a Cultura se constitui em jogo, na qual são aprendidos valores, regras, comportamentos a partir de um fazer cotidiano que perpassa geraçóes, sendo estruturado e tomado ora como consciência, ora como naturalização da vida diária.

No jogo há uma série de determinaçóes, campo de elementos que conduzem e tensionam as ligaçōes e relaçôes humanas, assim como seus efeitos. As determinaçôes, sobre a concepção de Nobert Elias, são a própria dinâmica e estrutura Cultural ${ }^{2}$, o trabalho, o lazer, as atividades educacionais, os comportamentos, o cuidado de si, entre outros, como descrita por Eagleton (2011). São essas determinaçôes que influenciam os diversos padrôes de comportamento, de projetos de vida, de política e desenvolvimento observados ao longo da história humana.

Nobert Elias destacou que os valores, os saberes locais, os comportamentos e a produção humana da vida diária constituem alicerces para a manutenção e a transformação, ao longo do tempo, de grupos sociais em seus territórios. A produção da vida diária e suas determinaçôes - a Ordem Cultural, segundo Elias (1970) - permite um conjunto de dados analíticos e de dispositivos para o entendimento das relaçóes de interdependências, que para o autor é a própria constituição da sociedade.

Os indivíduos carregam em suas trajetórias de vida funçôes representantes das determinaçóes da Ordem Cultural, que só podem ser exercitadas na relação com outros indivíduos - a interdependência (ELIAS, 1970).

Para Aquino (2012), a sociedade na visão eliasiana é uma categoria analítica em que não há separação de sociabilidade, ou seja, não se separa indivíduo e sociedade, ambos são pares de uma mesma relação da "[...] conjunção original de perspectivas micro e macrossociais" (ELIAS, 1990, p. 221), as identidades, dinâmicas e estruturas da sociedade se desenvolvem, evoluem e se contradizem.

Para Ribeiro (2005), a compreensão eliasiana da Ordem Cultural permite que a sociedade se dinamize, sem grandes preocupaçóes do fim que se espera chegar, mas tấo somente do sentido de continuidade, de futuro e projetos que cada grupo social deve ter em suas realizaçôes cotidianas.

A compreensão de continuidade e jogo de tensôes e forças de interdependências é para Martins (2002) uma questão do cotidiano, como categoria fundamental para tal abordagem. Para o autor, o cotidiano serve de análise às experiências locais, pois é no cotidiano como experiência da vida diária, na relação e na ação entre sujeitos com o seu local, que se desvelam as determinaçóes da Ordem Cultural.

Para Elias (1970), esta continuidade de futuro são "valências abertas" (ver Figura 1), espaços relacionais
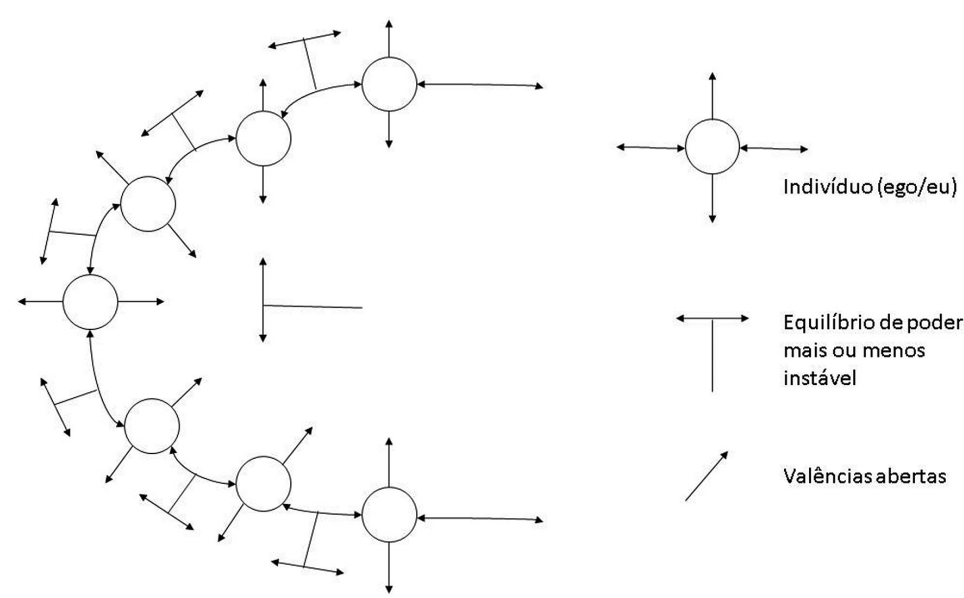

Valências abertas

Figura 1. Representação de indivíduos interdependentes para Nobert Elias. Fonte: Elias (1970, p. 15). 
para a entrada e aproximação de determinaçóes externas, advindas da dimensão Cultural histórica e da sociedade mais ampliada e global.

Enquanto diagrama, são as valências abertas espaços potenciais e frágeis para que processos de intervenção aconteçam e acionem mudanças nas dinâmicas e nas determinaçôes da Ordem Cultural. As tensóes causadas pelas valências abertas, sendo elas da ordem proposital ou náo, modificam os padróes naturalizados do cotidiano e propiciam a tomada de consciência sobre si, enquanto coletivo cultural.

\section{O desenvolvimento como liberdade: as contribuições de Amartya Sen}

Desde o final da década de 1990, as contribuiçôes do economista indiano Amartya Sen para a elaboração de políticas sociais e econômicas apresentaram um modelo teórico de desenvolvimento como expansão das liberdades individuais e coletivas. $\mathrm{O}$ autor compreende as capacidades e as determinaçôes culturais como categorias de manejo para estratégias de transformação micro e macrossociais.

A liberdade para Sen está muito próxima de qualidade de vida, pois se refere ao modo como as pessoas vivem, as escolhas que tomam e as razóes que as justificam. Um conjunto de variáveis que tornam o sujeito e seu coletivo "agente" de seus projetos de vida.

Estou usando o termo agente [...] de alguém que age e ocasiona mudança e cujas realizaçôes podem ser julgadas de acordo com seus próprios valores e objetivos, independentemente de as avaliarmos ou não também segundo algum critério externo. Este estudo ocupa-se particularmente do papel da condição de agente do indivíduo como membro do público e como participante de ações econômicas, sociais e políticas interagindo no mercado e até mesmo envolvendo-se, direta ou indiretamente, em atividades individuais ou conjuntas na esfera política ou em outras esferas (SEN, 2000, p. 33).

Sen (2000) explicita que a capacidade humana ${ }^{3}$ é um conjunto de habilidades, potencialidades, talentos e desejos diretamente influenciados e determinados pela Cultura, expressam as características de cada indivíduo, os padróes relacionais de um coletivo, o tipo e condução de sistema político e social convencionado e o modo como a geografia da localidade permite mais ou menos circulação humana. Isso para Sen (2000) é o modo como as determinações da Cultura agem sobre as diversas realidades humanas, produzindo efeitos ambíguos de privaçáo e de liberdade.

A compreensão de agentes ativos nos processos de transformação local, e, portanto, de seu desenvolvimento, é uma relação recíproca e fundamental à construção de projetos de vida coletiva. A indissociabilidade desse processo relacional permite compreender que todas as pessoas e local (participação e localidade/espacialidade) expressam mudanças e manutençôes da esfera micro e macrossocial.

Essas capacidades podem ser aumentadas pela política pública, mas também, por outro lado, a direção da política pública pode ser influenciada pelo uso efetivo das capacidades participativas do povo. Essa relação de mão dupla é central na análise aqui apresentada (SEN, 2000, p. 32).

Para o autor, a liberdade é a categoria fundamental para a elaboraçáo de projetos de desenvolvimento humano e social, o que destaca sua forte posição contrária a políticas de desenvolvimentismo econômico, e que, portanto, esta categoria deve ser o indicador quantitativo e qualitativo que modifique, em mão dupla, as políticas públicas e a vida cotidiana local. Para isso, Sen (2000) propóe sua teoria para fomentar projetos de manejo que visem ampliar e potencializar as capacidades humanas.

\section{Local e participação: par indissociável da liberdade e da Ordem Cultural}

Em projetos comunitários que tomem a abordagem em desenvolvimento local participativo, devem considerar o par: local e participaçáo, como conceitos-chaves e indissociáveis, pois este par é a estrutura de elaboração das açôes estratégicas que visem a liberdade como meio e fim de projetos nas determinaçôes da Ordem Cultural da vida cotidiana e coletiva.

\section{Para Martins (2002, p. 54),}

[...] a força do lugar (ordem local) reside no território compartilhado e identificado por uma consciência social e comunitária de entorno, cuja essência é a própria história vivida em comum.

A singularidade da convivência de um coletivo, que se expressa num dado local, influenciado pelas 
forças globais, focaliza a participaçáo como algo que pode ser vivido ou não, e que possibilita os processos de engajamento em desenvolvimento local, e que, portanto, para nós, desvela-se como uma questão comunitária. Assim, a questão comunitária é a participação, e como argumenta Costa (2008), esta é identificada como um elemento para o desenvolvimento local, na e a partir das histórias de vida em comunidade.

A concepção de local, segundo Martins (2002, p. 54), define-se pela escala das relaçóes interpessoais no espaço geográfico. As especificidades do lugar assentam-se na expressão consciente do cotidiano, por meio de elementos constituintes do capital social, como os limites geográficos, as divisóes de terra, a organização urbana e/ou rural, as organizações de trabalho, serviços de assistência, atividades de lazer, as domésticas, comunitárias etc., assim como as políticas globais e locais que dinamizam a própria localidade, gerando, segundo Martins (2002, p. 54), efeitos recíprocos de participação e interação na dimensão global - a concepção de "glocal".

A participação está além da ideia de sensibilização e de conscientização dos atores locais sobre suas interdependências, mas sim de engajamento ativo, crítico e democrático sobre as experiências cotidianas. Destituindo o lugar passivo e obediente de uma dada populaçáo, para assumir o papel de agentes ativos na Ordem Cultural. Para Martins (2002) e Sen (2000), o agente ativo é aquele que em conjunto de outros agentes deposita sua própria vitalidade na promoção de todos os sentidos do desenvolvimento.

Para Martins (2002), o local deve, então, se referir à Ordem Cultural como escala e natureza das inter-relaçôes pessoais da vida cotidiana, que oferece base concreta para a construção das identidades e da expansão das escolhas que se deseja viver, as liberdades.

\section{Os projetos de vida coletiva}

Segundo Correia (2014), os projetos de vida coletiva em DLP é um conjunto de propostas, objetivos e açôes estratégicas, construídos por todos os agentes envolvidos. Estes projetos também são conhecidos em DLP como agendamentos locais, pois expressam uma agenda das demandas locais, organizadas como metas e períodos a serem cumpridos, como afirmam Correia e Akerman (2015) e Ávila (2000).

Os projetos de vida coletiva ou agendamentos locais devem garantir pactuaçóes de vontades, desejos e necessidades dos agentes envolvidos, assim como o engajamento em atividades de seus interesses num fluxo contínuo da vida diária, como afirma Martins (2002).

Para Somech (2008), a implementação de açôes em DLP é uma intensa articulação e diálogo (COSTA, 2008) entre moradores de um local, representantes do poder público e órgãos públicos e/ou privados interessados na dinâmica e no uso Cultural do local. Trata-se, de acordo com Ávila (2000), de um processo educativo e estruturado por uma tríade: encontros, diálogos e construção de ferramentas.

\section{0 terapeuta ocupacional como articulador da abordagem em DLP}

O terapeuta ocupacional é um profissional que se dedica ao estudo e intervenção da Ocupação Humana, este é o seu domínio, e atribui questôes a ele relacionadas à saúde, à educação, ao social, à cultura, à segurança, entre outros, para responder às demandas populacionais, individuais e coletivas, orientadas tanto pelas estruturas que estas questóes são colocadas, como pelas políticas submetidas a elas.

A questão apresentada ao terapeuta ocupacional como questão comunitária diz respeito à participação de um coletivo no fluxo de suas atividades de vida diária. Estas, por sua vez, dizem respeito a processos relacionais assentados nas historicidades, territorialidade e identificaçóes com o local.

Segundo Correia (2014), o terapeuta ocupacional tem as atividades da vida diária como os elementos centrais da Ocupação, pois são elas que permitem o engajamento ativo dos sujeitos em projetos de vida e a construção de sentidos e significados. Aqui, Ocupação é compreendida como participação ativa, que para Córdova (2012) é a experiência relacional, recíproca e cultural nas atividades da vida cotidiana, permitindo a efetivação de projetos de vida e de pertencimento, a partir do próprio desempenho e engajamento nas atividades de cuidado de si, lazer, trabalho, educação, entre outras.

Até os expostos aqui, proponho que as ocupaçôes não são algo exterior aos sujeitos, uma expressão fenomênica da interioridade das pessoas, um método para alcançar a essência através desta aparência chamada ocupação. As ocupaçôes são práticas sociais, relacionais e, nelas mesmas, se constituem e produzem os sujeitos. Não há ocupação que tenha existência por si mesma. Toda a singularização é a manifestação em um sujeito, dentro de um campo ocupacional de caráter relacional (CÓRDOVA, 2012, p. 24). 
Para Correia (2014) e Correia e Akerman (2015), o terapeuta ocupacional é uma categoria chave, pois, tendo o domínio da Ocupação, utiliza as atividades da vida cotidiana para obter, em conjunto com as pessoas-alvo de sua intervenção, um conjunto de tecnologias para a real participação social.

Dessa forma, o terapeuta ocupacional pode ser um profissional estratégico para articular projetos em DLP, pois atua como um dispositivo, articulador e facilitador dos projetos de vida coletiva. Em desenvolvimento local participativo, o terapeuta ocupacional agencia com os agentes locais envolvidos as mudanças dos fatores negativos da localidade por meio de atividades da própria vida diária, a fim de obter a Ocupação como meio e fim de todo o processo, uma vez que a Ocupação é em si participação.

Nascimento (1990) já advertia os terapeutas ocupacionais sobre práticas em que as condiçóes concretas da vida e da ação das pessoas permaneciam fora do âmbito de intervenção desses profissionais e indicava um posicionamento de trabalho que fosse ao mesmo tempo técnico e político, que enfrentasse os problemas e os limites impostos às pessoas, restituindo-as à condiçấo de sujeito de sua própria história, participante do seu destino, descobrindo juntos caminhos possíveis.

$\mathrm{Na}$ abordagem em DLP, o terapeuta ocupacional tem de superar a ideia de atividade terapêutica e raciocínio clínico, devendo ser um profissional articulador da promoção e garantia da Ocupação por meio das atividades cotidianas como estratégias para projetos de desenvolvimento comunitário - projetos de vida coletiva; elaborando e compreendendo as questóes que faz a si mesmo, seus aportes e referenciais teórico-metodológicos e de que modo os compartilha com a populaçáo-alvo, tendo o compromisso técnico-ético-político sobre as experiências de liberdade, cooperação e participação nas determinaçôes culturais do cotidiano.

Para Correia e Akerman (2015), esse profissional, ao escolher modelos e instrumentos para a sua prática, deve ter, enquanto estrutura e dinâmica de raciocínio, a importância de exercer uma Terapia Ocupacional crítica sobre os aspectos que orientam a abordagem em DLP, para que efetivamente contribua na construção de melhorias das condiçóes de vida de um coletivo sob a égide da Ordem Cultural.

Os estudos sobre o papel do terapeuta ocupacional como articulador em DLP e as questôes comunitárias ainda são recentes, entretanto, é possível verificar experiências e boas práticas nos estudos de Correia (2014), Correia e Akerman (2015) e Costa (2008).

\section{Uma proposta de estrutura para a prática do terapeuta ocupacional em DLP}

Uma estrutura não é um quadro rígido a ser seguido em etapas, mas sim um percurso possível, um mapa que desenha trajetórias sobre perspectivas claras e objetivas, sem que a trajetória negue as complexidades e flexibilidades que qualquer dimensão da experiência de projetos de vida coletiva deve conter. Um projeto comunitário com abordagem em DLP parte da premissa de relaçôes de interdependências locais, participativas e de liberdade, pois não se constrói um projeto para sujeitos, mas sim com agentes.

As relaçôes de interdependência, como apresentadas por Elias (1970), pressupóe o jogo de poderes e negociaçóes que mobilizam estruturas de determinação da vida diária, e assim amplia-se um terreno de mobilidades e dinâmicas sobre os diversos papéis desempenhados em uma dada localidade, facilitando as tomadas de consciência sobre os próprios poderes tensionados nas inter-relações, bem como o agenciamento de açóes de um coletivo.

Para Correia (2014), uma estrutura de projeto em DLP deve oferecer possibilidades para o tensionamento da Ordem Cultural e para a construção de dispositivos para a operacionalização das açôes, orientadores da organização do coletivo.

Para Barros e El-Deir (2012), a proposição de uma estrutura de trabalho em DLP emerge da necessidade de gerenciar açóes estratégicas, portanto, bastante complexas, e que sem uma estrutura de trabalho objetiva impede a reunião e desenvolvimento das experiências, capacidades, habilidades e potências dos diversos agentes em um projeto comum e com visão de futuro. Para isso, a estrutura de trabalho em DLP, segundo as autoras, devem garantir três aspectos importantes: a mobilizaçáo dos agentes locais, o diagnóstico local e o planejamento das ações locais.

Destacam-se para a tentativa de uma representação gráfica do processo de trabalho em DLP (veja Figura 2), os pressupostos da interdependência da Ordem Cultural de Nobert Elias, com processos para a expansão de liberdades de Amartya Sen, sob os aspectos fundamentais a serem garantidos, conforme Barros e El-Deir (2012). Assim, o processo de trabalho é operacionalizado em quatro fases que devem promover:

1) a reuniáo entre agentes diversos, a fim de tomarem percepção sobre suas identificaçóes culturais numa dada trama Cultural e sobre as problemáticas e potencialidades dessa; 


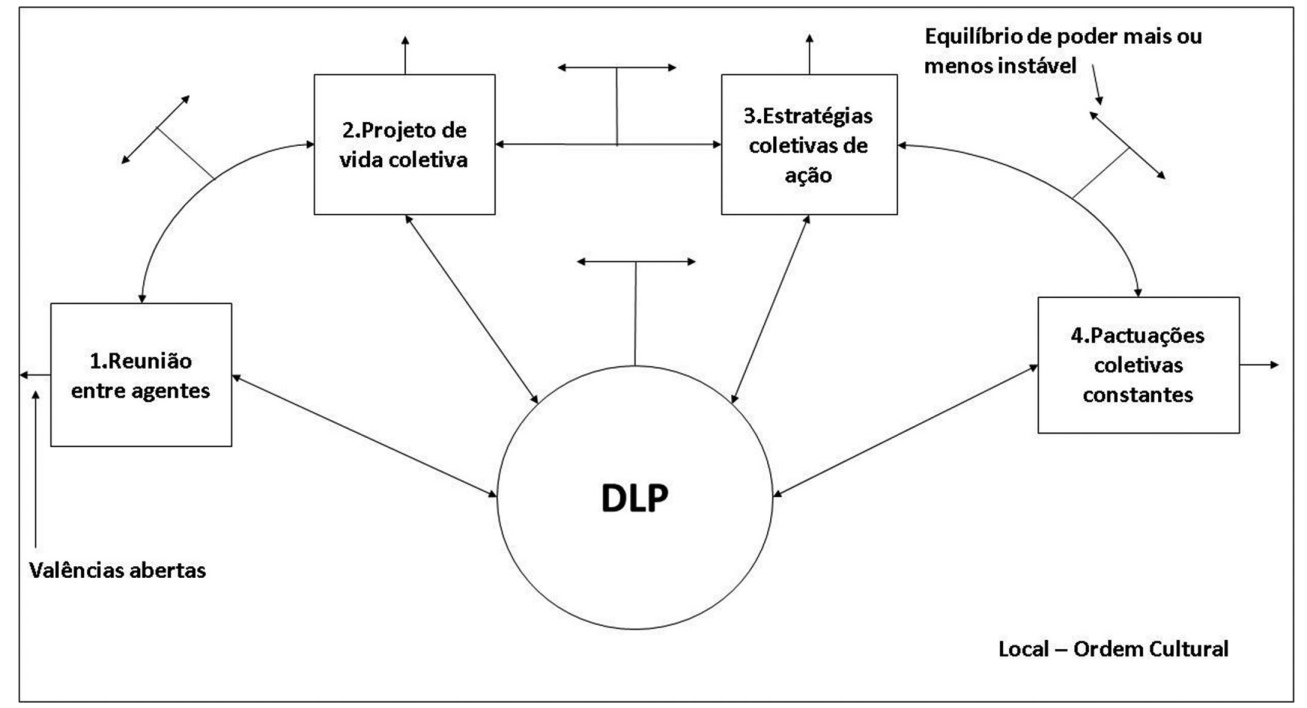

Figura 2. Uma estrutura para a prática em desenvolvimento local participativo. Fonte: elaborado pelos autores.

2) uma elaboração dialógica de projeto de vida coletiva, que garanta objetivos comuns centrados no local;

3) a construção de estratégias coletivas de ação, direcionadas à eliminação das barreiras que impeçam experiências de liberdade, e;

4) as pactuaçóes constantes dos atores envolvidos em torno dos projetos de vida, para a garantia e avaliação da continuidade das estratégias, dos mútuos apoios para sua efetivação e ampliação das capacidades individuais e coletivas.

Entre uma fase e outra, observam-se valências abertas, como afirma Elias (1970), que para o desenvolvimento local participativo dizem sobre as tensôes de poder na construção dos projetos de vida coletiva sob as determinaçốes da Ordem Cultural. As valências são os espaços de interdependências, que tensionam processos de desenvolvimento.

As fases direcionam-se para o processo, a continuidade de açóes, como propóe Martins (2002), que é o DLP, portanto, devem garantir que a participação seja o elemento que tece o conjunto. A garantia da participação só é possível por meio da organização e implementaçáo de atividades estratégicas, sendo estas as condutoras operacionalizáveis da estrutura de trabalho.

A primeira fase deve ser a reuniáo entre os agentes, podendo ser uma ação propositiva e organizada pelo terapeuta ocupacional, a fim de debater, dialogar e tomar percepções sobre a realidade experienciada no local vivido. Esta reuniāo deve envolver todos os interessados no uso da ordem Cultural local: moradores, poder público, órgãos públicos e privados como escolas, universidades, empresas, ONGs, serviços de saúde, assistência social, cultura etc.

Para Correia e Akerman (2015), o terapeuta ocupacional pode lançar máo de recursos diversos que promovam o caráter objetivo e dinâmico desta reunião, como rodas de conversa e instrumentos de coleta de dados sobre as estruturas da rede social de suporte e/ou mapeamentos com dados objetivos e subjetivos para apresentar aos atores envolvidos.

Os recursos de coleta de dados e mapeamentos podem ser feitos pelo próprio articulador terapeuta ocupacional, como a realização de entrevistas, visitas domiciliares, conversas informais para registro de narrativas etc., ou mesmo fazendo uso de instrumentos já disponíveis em meios de informação, como dados do IBGE, mapeamentos de saúde e assistência social e geoprocessamento de territórios (CORREIA; AKERMAN, 2015).

Com estas informaçóes, segundo Correia (2014) e Ávila (2000), a reunião se torna um encontro temático e educativo, na qual todos os envolvidos devem compreender as finalidades de estarem reunidos para debater sobre as perspectivas do desenvolvimento local participativo. As reunióes, ou rodas de conversa, podem ocorrer quantas vezes forem necessárias ao grupo, estabelecendo coletivamente um cronograma de encontros.

É importante que a compreensão de encontro, reunião ou rodas de conversa, seja claramente identificada pelos agentes envolvidos como uma atividade comunicacional (ÁVILA, 2000), ou um 
dispositivo comunicacional que permite a tomada de percepçáo sobre a realidade, como apontado por Schwartz (2008). Por tanto, o terapeuta ocupacional possui como tarefa facilitar e gerar coletivamente atividades, dispositivos de participação em torno da temática a ser discutida.

Este primeiro momento permite ao terapeuta ocupacional e aos membros envolvidos vivenciar o próprio saber local como um meio possível de apropriação da Ordem Cultural e tomar a percepção sobre o modo como questóes globais se aproximam e se distanciam da realidade local. Neste momento, o terapeuta ocupacional tem uma função essencial de proporcionar aos envolvidos devolutivas de suas próprias narrativas, podendo utilizá-las como palavras-chaves para a percepçáo, podendo transformá-las em questôes e situaçóes-problemas para que o grupo avance e aprofunde o diálogo.

O próximo caminho é utilizar todas essas informaçóes dialogadas para construir um quadro de situaçôes problemas e situaçóes potenciais, ou seja, questôes que dificultam o desenvolvimento local e situaçôes/recursos do próprio contexto local que facilitam o desenvolvimento.

O terapeuta ocupacional contribui com os atores envolvidos na transformaçáo das situaçóes-problemas em demandas que devem ser acordadas de forma objetiva entre todos os envolvidos. Avança-se para a segunda fase.

Estas demandas em conjunto devem constituir um projeto de vida coletiva. As demandas devem ser pragmáticas, com curto, médio e longo prazo, de forma que a temporalidade daquilo que se almeja alcançar seja mote de esperança para projetos de vida, na qual a percepção daquilo que é mais ou menos difícil de se atingir é claro para todos os envolvidos.

$\mathrm{Na}$ terceira fase do processo, constrem-se estratégias de açáo coletiva. As estratégias também devem ser acordadas por todos, assim como a identificação e representação daqueles que irão se responsabilizar de forma individual ou grupal sobre determinada demanda. $\mathrm{O}$ processo náo deve ser fragmentado em simples tarefas, e o terapeuta ocupacional tem como função garantir que todos estejam de pleno acordo com aquilo que eles deliberarem.

Encontros agendados devem ser garantidos, para que pactuaçóes constantes sejam firmadas e devolutivas sejam dadas durante o processo do projeto de vida coletiva, sendo esta a quarta etapa do processo. Em qualquer momento, as fases podem ser retomadas, sem que se percam os resultados já produzidos em uma fase anterior.
Para Correia (2014), Barros e El-Deir (2012) e Martins (2002), o encontro grupal dos envolvidos permite que um senso de mútua ajuda seja ressoado em todos e que o grupo use de sua diversidade cultural e de suas capacidades para mobilizar uns aos outros, mesmo aqueles que não fazem parte do grupo envolvido na elaboração e condução direta do projeto.

Ainda nos encontros de pactuação das estratégias de ação, os envolvidos devem, com a ajuda do facilitador, avaliar de que modo o projeto proposto está contribuindo para diminuir e/ou eliminar as barreiras que impedem o desenvolvimento.

Para Correia e Akerman (2015), o terapeuta ocupacional pode contribuir facilitando o grupo a organizar as informaçóes e na construção de estratégias para qualificar o andamento do processo, tanto a partir de recursos e tecnologias de seu saber pessoal e profissional, como facilitar o grupo a construir e identificar tecnologias do saber local e coletivo.

É importante o terapeuta ocupacional identificar que, ao passo que as atividades planejadas, implementadas e avaliadas vão sendo operacionalizadas, estas em seu conjunto se constituem um arcabouço quantitativo e qualitativo de saberes locais, que em DLP chama-se de Tecnologia Social - TS.

A construçâo do conceito de TS se propóe nesta perspectiva qual "conjunto de técnicas e metodologias transformadoras, desenvolvidas e/ou aplicadas na interação com a população e apropriadas por ela, que representam soluçóes para inclusão social e melhoria das condiçóes de vida" (INSTITUTO..., 2007, p. 29).

O resultado do conjunto articulado de atividades estratégicas, operacionalizando a participação dos agentes, toma por base as múltiplas dimensóes humanas e suas interaçóes de ensino e aprendizado mútuos, como nas afirmaçôes de Ávila (2000) sobre a tríade do processo em DLP: encontros, diálogos e construçáo de ferramentas. Este cenário permite o desenvolvimento de um ambiente democrático, de sociabilidades, cidadania e inovaçóes para a promoção em DLP.

[...] se há interação entre TS e DLP, não cabe também uma situação de submissão ou de hierarquia. No momento que uma comunidade se articula em seu espaço para aumentar a economia local, para gerar mais trabalho e renda, para buscar a melhoria da qualidade de vida dos seus moradores e para apropriar-se de tecnologias, ela se encontra em um processo de desenvolvimento humano para os homens e as mulheres envolvidos e realizando TS (FELIX et al., 2009, p. 21). 


\section{Considerações finais}

A abordagem em desenvolvimento local participativo se apresenta como um importante arcabouço estrutural para as açóes do terapeuta ocupacional, que tenha como focalização de sua prática a questão comunitária e seus interesses, conscientes ou náo, de desenvolvimento.

A sistematização de projetos em desenvolvimento local participativo necessita maior aprofundamento, tempo, acúmulo de experiências e evidências para que possam produzir estruturas metodológicas substanciais, a fim de verificar as significativas contribuiçóes da Terapia Ocupacional, num universo complexo e interdisciplinar que envolve esta abordagem.

Nesse ponto, algumas questôes podem auxiliar e orientar o trabalho. A quais questóes da Terapia Ocupacional interessa o uso da abordagem em desenvolvimento local? E a quais questóes do desenvolvimento local e global interessa a Terapia Ocupacional? Enquanto abordagem em desenvolvimento local participativo, fala-se da apropriação de uma área - Terapia Ocupacional Cultural? Terapia Ocupacional Social? Quais as possibilidades apresentadas, criadas e compartilhadas para outras áreas, como a Saúde, a Educação e para o planejamento e gestão de políticas públicas? Como a Terapia Ocupacional pode oferecer de forma objetiva as contribuiçóes de seu domínio - a Ocupação como participação nas atividades da vida diária - para projetos e programas de desenvolvimento mais amplos, que não estejam somente centrados no indivíduo, enquanto objeto analítico da clínica? São perguntas que ainda não estâo respondidas, e não encerra aqui respondê-las, há folego para mais desdobramentos.

O que se propóe aqui em desenvolvimento local participativo ao Terapeuta Ocupacional é um processo e possibilidade da construçáo de um senso crítico do coletivo sobre si mesmo, como uma expressão das determinações da Ordem Cultural. As capacidades como condutoras da eliminação de barreiras, que privam a liberdade e o pleno desenvolvimento humano e local, devem ser o foco do terapeuta ocupacional, a partir da articulação e elaboração coletiva de atividades de vida diária estratégicas no engajamento em projetos de vida coletiva.

Espera-se que o terapeuta ocupacional tome para si o domínio da Ocupação como participação ativa, pois é no contínuo deste que se registra a pluralidade e complexidade das identidades locais sobre o solo dinâmico da Ordem Cultural.

\section{Agradecimentos}

Ao Prof. Dr. Marco Akerman, da Faculdade de Saúde Pública da Universidade de Sáo Paulo (USP). Antônio Bongiovanni e Yara Bongiovanni, coordenadores do Projeto Rondon no estado de Sáo Paulo. Aos colegas de trabalho do Departamento de Terapia Ocupacional da UFRJ e da Faculdade de Medicina do ABC.

\section{Referências}

AQUINO, S. L. Consideraçóes sobre o conceito de civilização em Nobert Elias. Revista Espaço Acadêmico, Maringá, ano XII, n. 138, p. 138-48, 2012.

ÁVILA, V. F. Pressupostos para a formação educacional em desenvolvimento local. Revista Internacional de Desenvolvimento Local - INTERAÇÓES, Mato Grosso, v. 1, n. 1, p. 63-76, 2000.

BARROS, M. B. B.; EL-DEIR, S. G. Desenvolvimento Local Participativo - uma cidade pensada como campo educativo e de participação. Revista Transformare ADM, Recife, v. 2, n. 2, p. 1-10, 2012.

CÓRDOVA, A. G. Enfoque y práxis en terapia ocupacional. Reflexiones desde una perspectiva de la terapia ocupacional crítica. TOG (A Coruña), Galícia, v. 9, n. 5, p. 18-29, 2012.

CORREIA, R. L. O uso do ecomapa para análise de redes sociais de suporte egocentrada: estratégia para o desenvolvimento local participativo. 2014. 185 f. Dissertação (Mestrado em Ciências da Saúde) - Faculdade de Medicina do ABC/Fundação ABC, Santo André, 2014.

CORREIA, R. L.; AKERMAN, M. Desenvolvimento Local Participativo, Rede Social de Suporte e Ocupação Humana: relato de experiência em projeto de extensão. Revista de Terapia Ocupacional da Universidade de São Paulo, São Paulo, v. 26, n. 1, p. 159-165, 2015.

COSTA, S. L. Os sentidos da comunidade: produção intergeracional de memória coletiva na ilha das Caieiras, Vitória-Es. 2008. 337 f. Tese (Doutorado em Psicologia - Psicossociologia das Comunidades e Ecologia Social) Universidade Federal do Rio de Janeiro, Rio de Janeiro, 2008.

EAgleton, T. A ideia de cultura. São Paulo: Editora Unesp, 2011.

ELIAS, N. Introdução à sociologia. Lisboa: Editora 70, 1970.

ELIAS, N. O processo civilizador: uma história dos costumes. Rio de Janeiro: Jorge Zahar, 1990.

FELIX, W. J. S. et al. A relação entre tecnologia social e desenvolvimento local participativo: a apaeb e o instituto palmas como expressão destes vínculos. Revista $A D M$. $M A D E$, Rio de Janeiro, v. 13, n. 2, p. 16-33, 2009. 
INSTITUTO DE TECNOLOGIA SOCIAL - ITS. Conhecimento e cidadania 1: tecnologia social. Guarulhos: Publisher, 2007.

MARTINS, S. R. O. Desenvolvimento local: questôes conceituais e metodológicas. Interaçóes: Revista Internacional de Desenvolvimento Local, Campo Grande, v. 3, n. 5, p. 51-59, 2002.

NASCIMENTO, B. A. O mito da atividade terapêutica. Revista de Terapia Ocupacional da Universidade de São Paulo, São Paulo, v. 1, n. 1, p. 17-21, 1990.

RIBEIRO, L. C. Nobert Elias e a história cultural. In: CARVALHO, A. B.; BRANDÃO, C. F. (Org.). Introdução à sociologia da cultura: Max Weber e Nobert Elias. São Paulo: Avercamp, 2005. p. 89-104.
SCHWARTZ, G. Arranjos comunicativos locais (ACLs) e desenvolvimento local. In: DOWBOR, L.; POCHMANN, M. (Org.). Politicas para o desenvolvimento local. São Paulo: Fundação Perseu Abramo, 2008. p. 67-82.

SEN, A. Desenvolvimento como liberdade. São Paulo: Cia. das Letras, 2000.

SILVEIRA, C. Desenvolvimento local e novos arranjos socioinstitucionais: algumas referências para a questão da governança. In: DOWBOR, L.; POCHMANN, M. (Org.). Políticas para o desenvolvimento local. São Paulo: Editora Fundação Perseu Abramo, 2008. p. 41-66.

SOMECH, N. Construção social da cidade: desenvolvimento local e projetos urbanos. In: DOWBOR, L.; POCHMANN, M. (Org.). Politicas para o desenvolvimento local. São Paulo: Editora Fundação Perseu Abramo, 2008. p. 17-40.

\section{Contribuição dos Autores}

Ricardo Lopes Correia trabalhou na concepção do texto, organizaçáo de fontes e referências, redaçáo e revisão do texto. Camila Santiago da Rocha: trabalhou na organização de fontes e referências, redação e revisão do texto. Ambos os autores aprovaram a versão final do texto.

\section{Notas}

${ }^{1}$ Para Elias (1970), as identidades e/ou personalidades (psicogênese) e dinâmicas e estruturas da sociedade (sociogênese) se desenvolvem, evoluem e se contradizem de forma indissociável e insolúvel. Nobert Elias teve forte influência, para a produção de suas obras, dos grandes eventos científicos da década de 1930, como a Teoria da Relatividade e a Psicanálise, que contribuíram fortemente para sua ideia de convergência da sociogênese e psicogênese. Elias não dicotomiza estes eixos fundantes e os utiliza como ferramentas de compreensão e análise dos padróes culturais da sociedade e mudanças consecutivas, ou seja, para Elias concomitantemente estruturas sociais da Cultura se modificam, ao passo que as estruturas de personalidade se alteram, e vice-versa.

${ }^{2}$ Para Ribeiro (2005), Elias ousou compreender questōes sociais históricas a partir das questóes e dos padrōes da Ordem Cultural estabelecidas no dia a dia de grupos sociais, por isso a importância das diversas obras de Elias serem de achados empíricos. A busca pela compreensão das tensões e mudanças de padróes sociais através da História Cultural, e portanto do jogo de determinaçóes que propôs Elias, gerou desde o começo dos anos de 1930 uma intensa crise, até os dias atuais, de qual perspectiva de Cultura este fabuloso autor se apoiou. De forma sólida, Elias demonstrou uma capacidade sistêmica e complexa de historiografar a sociedade do início do século XX, com requintadas ferramentas sociopolíticas que também serviram e servem a Sociologia da Cultura.

${ }^{3}$ O autor, no livro Desenvolvimento como liberdade (SEN, 2000) expóe os pressupostos de um modelo teórico sobre a liberdade como indicador do desenvolvimento humano e social, e sustenta a abordagem das capacidades humanas como um processo de articulação e organização entre estruturas micro e macrossociais. 